\title{
Effect of Trauma on Mental Health of Parents and Children in the Middle Area of the Gaza Strip
}

\author{
Thabet $\mathrm{AA}^{1 *}$ and Panos Vostanis ${ }^{2}$ \\ ${ }^{1}$ Emeritus Professor of Child and Adolescent Psychiatry, Al Quds University, Palestine \\ ${ }^{2}$ Department of Neuroscience, University of Leicester, United Kingdom
}

Submission: July 29, 2017; Published: August 24, 2017

*Corresponding author: Thabet AA MD, PhD, Emeritus Professor of Child and Adolescent Psychiatry, School of Public Health, Al Quds University, Jerusalem, Palestine, Email: abdelazizt@hotmail.com

\begin{abstract}
Aim: This study was undertaken after one year of the disengagement plan and withdrawal of Israeli Occupation forces from Gaza Strip with the aim to determine the effect of shelling and other traumatic events on mental health of parents and children.

Method: The study includes 200 parents and 200 children age 9-18 years who were assessed by self- completed questionnaire.

Results: The results estimated mean traumatic experiences for parents were 8.42, prevalence of PTSD in parents was 60\%; anxiety disorder 26.5\%. For children, mean traumatic events were 7.88, prevalence of PTSD in children was 70.1\%; anxiety disorder (33.9\%), general mental health problems rated by parents (42.7); conduct disorder (36.8\%); hyperactivity (22.8\%), emotional problems (24.4\%), peers problems (60.1\%), and prosocial problems (20.2\%). There was correlation between trauma of children and PTSD of children, intrusion, avoidance, and arousal. No gender differences in both parents and children in PTSD. Parents PTSD were associated with their children PTSD. PTSD of children was significantly associated with total traumatic events of parents, anxiety of parents, of PTSD of parents, intrusion symptoms of parents, avoidance, and arousal symptoms. Also anxiety of children was significantly correlated with parent's anxiety.
\end{abstract}

Clinical implications: These findings are discussed in relation to need for crisis intervention programmes in north of Gaza and West of Gaza and psychosocial programmes for both parents and children.

Keywords: Shelling; Parents; Children; PTSD; Anxiety; General mental health; Gaza Strip

\section{Introduction}

On September 2000, the Al Aqsa Itifada erupted. Palestinian children and families have been exposed to a variety of traumatic events, ranging from hearing of killing, to bombardment by helicopters at the entire Gaza Strip. The current conflict differs from the previous Intifada, in which events such as night and day raids were common occurrence in previous Intifada (1987-1993). Shelling and bombardment became the main them of trauma to children and families especially after the disengagement plan from Gaza Strip in 2005. Even after the withdrawal of the Israeli occupation forces from Gaza Strip, shelling of north and east of Gaza Strip is still a daily act of violence against the Palestinian. Added to this, the sonic sound of jetfighters, bombardment by helicopters, jet fighters, and pilot free aeroplanes including assassinations of Palestinian Militants. According to UN report [1] Palestinian death toll reaches 202 as 'Operation Summer Rains' extends into its tenth week The nearly two-month long Israeli military operation in the Gaza Strip continues to exact a heavy toll on the 1.4 million Palestinians living in the Gaza Strip. Two hundred and two (202) Palestinians, including 44 children have been killed since 28 June, when 'Operation Summer Rains' (the Israel Defense Forces (IDF) name for the offensive) began. Since 28 June, the Israel Air Force (IAF) launched at least 267 air strikes attacks on the Gaza Strip. Common feelings and reactions in the aftermath of a traumatic event include sadness, anger, rage, fear, numbness, stress, feeling of helplessness, feeling jumpy or jittery, moodiness or irritability, change in appetite, difficulty sleeping, experiencing nightmares, avoidance of situations that are reminders of the trauma, problems concentrating, and guilt because of survival or lack of harm during the event [2].

PTSD prevalence is higher where exposure to war, statesponsored terrorism, or interpersonal violence is more common than in the U.S. A recent epidemiological study estimated that the prevalence of lifetime PTSD is 37\% in Algeria, 28\% in Cambodia, $16 \%$ in Ethiopia, and $18 \%$ in Gaza [3]. In the last six years, there was changing in the intensity and type of traumatic events. Palestinian children were exposed [4] found that the most common traumatic events reported by Palestinian children were: seeing victims' pictures on television (92.3\%), followed 
by witnessing bombardment and shelling (83.6\%). [4] In study of Palestinian mothers and children found that $34.3 \%$ of the children fulfilled criteria of PTSD. In another comparative study of children witnessed bombardment of their homes, 59.3\% of children reported PTSD. Anxiety symptoms were also common, $22 \%$ of the children had anxiety disorder [5]. In another study of 944 aged 10-19 years Palestinian children in the Gaza Strip [6] found that $32.7 \%$ of children were rated as having PTSD [7] in study of Palestinian children found that $24 \%$ of children reported PTSD. In study [8] of 349 children from Gaza Strip and West Bank found that $39.2 \%$ of children from the Gaza Strip reported post traumatic stress disorder (40 and above in IES) compare to $34 \%$ in the West Bank.

In study of children and their mothers found that there was significant association between trauma of children and their mothers [4]. In study the prevalence of posttraumatic stress disorder (PTSD) symptoms and their predictors among Rwandans. Among the 2091 total participants, 518 (24.8\%) met symptom criteria for PTSD [9]. In a cross-sectional, face-to-face interview conducted in Khmer language on a random sample of households from the Cambodian community in the United States, between October 2003 and February 2005. A total of 586 adults aged 35 to 75 years who lived in Cambodia during the Khmer Rouge reign and immigrated to the United States prior to 1993. High rates of PTSD (62\%) and major depression (51\%) were found. PTSD and major depression were highly co morbid and each showed a strong dose-response relationship with measures of traumatic exposure [10]. In a cross-sectional survey conducted between March 2000 and July 2002 with a population-based sample of 1358 war survivors who had experienced at least 1 war-related stressor (combat, torture, internal displacement, refugee experience, siege, and/or aerial bombardment) from 4 sites in former Yugoslavia. Participants reported experiencing a mean of 12.6 war-related events, with 292 (22\%) and 451 (33\%) having current and lifetime posttraumatic stress disorder (PTSD), respectively, and 129 (10\%) with current major depression [11]. The aim of the study is to determine the impact traumatic events on mental health of parents and children in Middle area of the Gaza Strip.

\section{Participants}

The study population included 106 fathers and 106 mothers with their children living middle area of the Gaza Strip. Families with 2 children aged from 9-18 years were included. A total number of 212 parents and 212 children responded to the Instruments and Self-report measures. A questionnaire pack was used in Arabic language some scales were developed for this study (such as GTC) while other scales were used before in the same culture. [1] Socio demographic status which gathered from parents and children by questionnaire includes sex, age, place of residence, type of housing, number of sibling and rooms, father education and mother education etc. [2] Gaza Traumatic Checklist was used with most common traumatic experiences could face in the Gaza Strip including shelling of the area of living. This scale had 10 items with Yes and no answer. The alpha Chronbach for this scales was 0.67 , split half was 0.45 . Posttraumatic Stress Disorder Checklist for parents [3] contains 17 items adapted from Diagnostic and Statistical Manual of Mental Disorders, Fourth Edition [2] PTSD symptom criteria, taking approximately 5 minutes to administer. Respondents are asked to rate on a 5-point Likert scale (1=not at all to $5=$ extremely) the extent to which symptoms bothered them in the previous month. The PCL demonstrates adequate internal consistency ( $\alpha=.94)$. In this study internal consistency of the scale, calculated using Cronbach's alpha was also high ( $\alpha=0.82)$; split half was 0.69. [4] Taylor's Manifest Anxiety Scale (MAS) [12] which scale consisted of items selected from the Minnesota Multiphase Personality Inventory Taylor's MAS was reported to be useful in identifying adults with chronic anxiety $[13,14]$. We used the Arabic version with 50 items and answer is «Yes» or «No». The score of 0-26 (no anxiety), 27-32 (Mild anxiety), 33-40 (severe anxiety), and 41 and above (very severe anxiety). Reliability of the test has been found to range between 0.81-0.92 in Arab populations [15]. This scale was also used in Gaza Strip and validated for Palestinian society [16]. In this study internal consistency of the scale, calculated using Cronbach's alpha was also high $(\alpha=0.79)$; split half was 0.71 .

\section{The following instruments were used for children}

Gaza Traumatic Events Checklist was used with most common traumatic experiences could face in the Gaza Strip including shelling of the area of living. This scale had 10 items with Yes and no answer. The alpha Cronbach's for this scales was 0.79 , split half was 0.40 .

\section{Children's revised impact of event scale (CRIES-13) [17]}

All participants completed the CRIES-13, which include all of the items on CRIES-8 taken from the original Impact of Events Scale [18], as well as 5 items derived from the arousal criterion in the DSM-IV [2]. Individual items are rated according to the frequency of their occurrence during the past week (None $=0$, rarely $=1$, Sometimes $=3$, and $A$ lot $=5$ ) and in relation to a specific traumatic events written at the top of the scale. In this study we used the revised IES which was translated from English to Arabic and back Translated and no differences in both translations was found [8]. The intrusion items include 1,4,8,9, avoidance items include 2,6,7,10, and hyper arousal items include 3,5,11,12,13. The psychometric properties of CRIES (13-item) IES were evaluated in a large population of children exposed to warfare in Croatia, Bosnia and Herzegovina [19]. PTSD estimated a cutoff score of 30 and above as presence of PTSD. [17] Found that reliability of the scale using Cronbachs's alpha was 0.80; regarding the three subscales, Cronbach's alpha for the intrusion items was 0.70 ; and for the avoidance items it was 0.73 . However, lower internal consistency was found for the five new arousal items, with Cronbach's alpha at 0.60 . In this study the internal consistency of the scale, calculated using Cronbach's alpha was 
also high $(\alpha=.75)$; the split half reliability of the scale was 77 .

\section{Revised Children's Manifest Anxiety Scale (RCMAS) [13]}

The RCMAS is a standardized 37 -item self-report questionnaire for children of $6 \pm 19$ years of age [13] it measures the presence or absence of anxiety-related symptoms (yes/no answers) in 28 anxiety items and 9 lie items. A cut-off total score of 18 has been found to predict the presence of anxiety disorder [18]. In this study internal consistency of the scale, calculated using Cronbach's alpha was also high $(\alpha=.77)$; the split half reliability of the scale was .76 .

\section{Strengths and Difficulties Questionnaire (SDQ) [20]}

The SDQ for parents or teachers of children $4 \pm 16$ years is a standardized questionnaire, which includes 25 items, which are the same for each age group for the different informants [13]. Out of the 25 items, 14 describe perceived difficulties, 10 perceived strengths and one is neutral ('gets on better with adults than with other children'). Each perceived difficulties item is scored on a $0 \pm 2$ scale (not true, somewhat true, certainly true). Each perceived strengths item is reversely scored, i.e. 2: not true, 1: somewhat true, 0: certainly true. The 25 SDQ items are divided in the scales of Hyperactivity, Emotional Symptoms, Conduct Problems, Peer Problems and Prosocial Scale. A score is estimated for each scale and a total difficulties score for the four scales (excluding prosocial behavior, which was considered different from psychological difficulties). In this study the reliability of the scales using Alpha Chronbach was 0.78 Split half is 0.79 .

\section{Study Procedure}

The data collection was carried out by thee trained professionals with the supervision of the first author. The data collection was done from $6^{\text {th }}$ June to $29^{\text {th }}$ June 2006 before the current incursion of Gaza Strip. The families were interviewed in their homes. One of the difficulties during this study is that during our interview there was shelling of the area and we have to run out of house to safer place and then to come back to finish the interview. The last two days was so hard to go and ask people to participate because there were strong signs that they will be new incursion of the area and this happened few days later and still ongoing till now.

\section{Statistical analysis}

Data entry and analysis will use a Statistical Package for the Social Science (SPSS, Version 22). Frequency and percent were used to express quantitative data of type of traumatic experience, post-traumatic stress disorder, anxiety of children and parents. For continuous variables means and standard deviation were reported. For differences between means of two group's parametric test were used such as t-test to compare sex of children and parents in mean of trauma, PTSD, anxiety. While,
ANOVA tests were used for measuring differences between more than two groups of continuous variables such trauma and place of residence, trauma, PTSD, anxiety and other mental health problems of children and parents. The researcher was used least significant difference (LSD) test after one way ANOVA test, to explore further and compare the mean of one group with the mean of another. Pearson's correlation coefficient was used to test the association between traumatic experiences, PTSD, anxiety, SDQ scores. Stepwise multiple regression analyses for the severity PTSD by children was entered as dependent variable and each traumatic event as independent variables. Another Stepwise multiple regression analyses for the severity PTSD by parents was entered as dependent and each traumatic event as independent variables. The 0.05 alpha levels were accepted as a sign for statistical significance for all the statistical procedures (Figure 1).

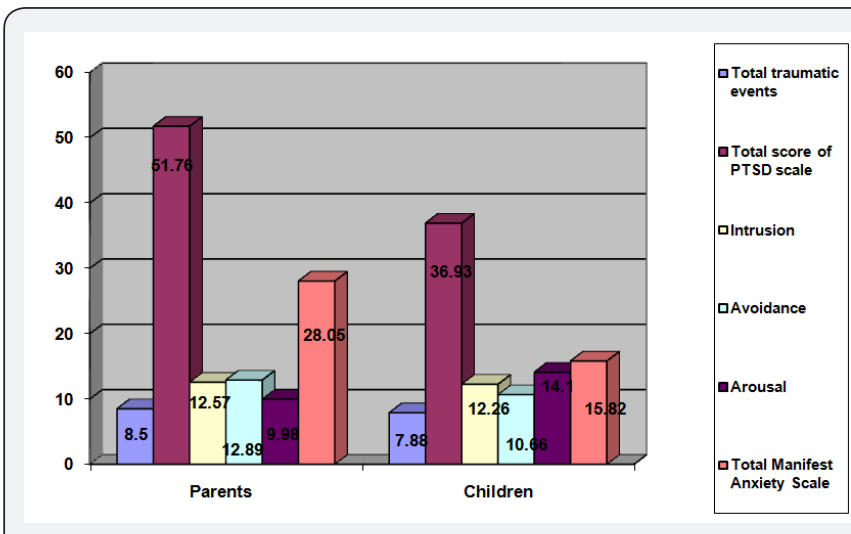

Figure 1: Means and SD of effect of trauma, PTSD, Anxiety, mental health of children and parents

\section{Results}

\section{Socio demographic data}

As shown in Table 1, 101 boys responded which represented $50.8 \%$ and the 98 of 100 girls responded which represented $49.2 \%$. The mean age of boys was 12.8 years ( $\mathrm{SD}=2.5$ ); while the mean age of girls was $13.2(\mathrm{SD}=2.51)$. Palestinian families are consisted of large number of children, $19.5 \%$ had 4 and less children, $46 \%$ of families had 5-7 children, and $34.5 \%$ had 8 and more children. Twenty four per cent children live in city, $51 \%$ live in villages, and $25 \%$ live in the camp. Our sample consisted of 100 families which mean that 100 father and similar number of mothers. Fathers mean age was 43.6 years ( $S D=7.14$ ), while mothers mean age $=39.48$ years $(\mathrm{SD}=6.83)$. As a result of current conflict, $51 \%$ of fathers were unemployed and $29 \%$ were civil employee and the rest were simple and professional workers. While almost $99 \%$ of mothers were housewives. Almost $82 \%$ of fathers finished secondary education, while $87 \%$ of mothers finished similar level of education. Due to high level of unemployment, $65 \%$ of families had less than 270 US \$ monthly income (Table 1). 
Table 1: Socio demogrophic characteristics of the study population children $(\mathrm{N}=212)$.

\begin{tabular}{|c|c|c|}
\hline Items & $\mathbf{N}$ & $\mathbf{\%}$ \\
\hline Sex & 105 & 49.5 \\
\hline Boy & 107 & 50.5 \\
\hline Girl & $\begin{array}{c}\text { Boys mean } \\
\text { age of children in } \\
\text { years }\end{array}$ & $\begin{array}{c}\text { Girls mean age=12.68 } \\
\text { ( SD=2.70) }\end{array}$ \\
\hline 9-12 years & 103 & 48.6 \\
\hline 13-15 years & 69 & 32.5 \\
\hline 16-18 years & 40 & 18.9 \\
\hline Number of siblings & 25 & 11.8 \\
\hline 4 and less & 127 & 59.9 \\
\hline 5-7 siblings & 60 & 28.3 \\
\hline 8 and more siblings & & \\
\hline Type of residence & 68 & 32.1 \\
\hline City & 66 & 31.1 \\
\hline Village & 78 & 36.8 \\
\hline Camp & & \\
\hline
\end{tabular}

\section{Types of traumatic events in children}

Due to the current conflict and continuity of traumatic experiences, the most common traumatic events children reported was watching mutilated bodies and wounded people on TV 98.5\%, hearing shelling of the area by artillery (94.9\%), and hearing sonic sounds of the jetfighters (92.9\%), while the least common traumatic experience was hearing about killing of a close relative (61\%). Our children mean traumatic events was 7.88 (SD=2.55) (Figure 2).

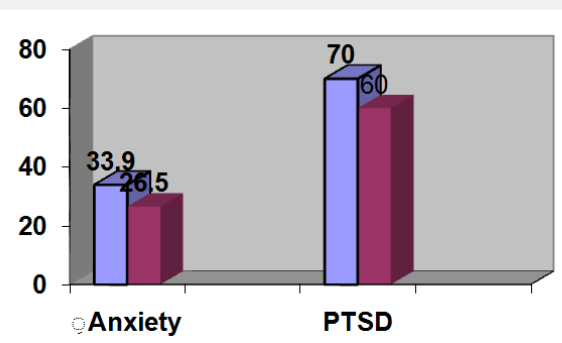

\section{口Child}

- Parents
Figure 2: PTSD and Anxiety in children and parents (in percentage).

To study differences in total trauma, and sex of children, a $\mathrm{T}$ independent test was performed in which children sex was the dependent variable and total number of traumatic events as independent variable. The result showed that there were no statistically significant differences in total number of traumatic events and sex of children. In order to test the differences of other socio demographic variables such as number of siblings, place of residence, family monthly income, and age of children, a One Way ANOVA was performed in which each of the socioeconomic variable was the independent variable and total traumatic experiences was entered as dependent variable. Post hoc result showed that there were statistically significant differences in total number of traumatic events and living in villages and families with monthly income 561 US \$. Post hoc test showed that children coming from families living in villages had more number of traumatic events than the other two groups $(F=3.5$, $\mathrm{p}=0.03$ ) and children coming from families with monthly income of 561 US \$ had more number of traumatic events than the other two groups $(\mathrm{F}=4.40, \mathrm{p}=0.03)$ (Table 2$)$.

Table 2: Socio demogrophic characteristics of the study population parents $(\mathrm{N}=212)$.

\begin{tabular}{|c|c|c|}
\hline Items & No & $\%$ \\
\hline $\begin{array}{l}\text { Mean age of parents } \\
\text { in years }\end{array}$ & $\begin{array}{c}\text { Father mean age }= \\
43.6(\mathrm{SD}=7.14)\end{array}$ & $\begin{array}{c}\text { Mother mean age }= \\
39.48(\mathrm{SD}=6.83)\end{array}$ \\
\hline \multicolumn{3}{|l|}{ Place of residence } \\
\hline City & 68 & 32.1 \\
\hline Village & 66 & 31.1 \\
\hline Camp & 78 & 36.8 \\
\hline \multicolumn{3}{|l|}{ Paternal job } \\
\hline Unemployed & 51 & 51 \\
\hline Simple worker & 10 & 10 \\
\hline Professional worker & 5 & 5 \\
\hline Employee & 29 & 29 \\
\hline Merchant & 4 & 4 \\
\hline \multicolumn{3}{|l|}{ Paternal education } \\
\hline Less than secondary & 48 & 45.3 \\
\hline $\begin{array}{l}\text { Secondary and } \\
\text { diploma }\end{array}$ & 42 & 39.6 \\
\hline University degree & 16 & 15 \\
\hline \multicolumn{3}{|l|}{ Maternal job } \\
\hline House wife & 102 & 96.23 \\
\hline Employee & 4 & 3.7 \\
\hline \multicolumn{3}{|l|}{ Maternal education } \\
\hline Less than secondary & 33 & 30.8 \\
\hline $\begin{array}{l}\text { Secondary and } \\
\text { diploma }\end{array}$ & 64 & 59.8 \\
\hline University degree & 10 & 9.3 \\
\hline \multicolumn{3}{|l|}{$\begin{array}{l}\text { Family monthly } \\
\text { income }\end{array}$} \\
\hline $\begin{array}{l}\text { Low (Less than } 270 \\
\text { US \$) }\end{array}$ & 130 & 60 \\
\hline $\begin{array}{l}\text { Middle (271-560 } \\
\text { US \$) }\end{array}$ & 27 & 13.5 \\
\hline High (561 US \$) & 43 & 21.5 \\
\hline
\end{tabular}

\section{Post traumatic stress disorder in children}

Children reported a different reactions to traumatic events, the most common reactions were: insomnia $(40.5 \%)$, exaggerated startle (39\%), try to remove memories from mind (39\%), and psychological reactivity (38.5\%). Children mean PTSD according to IES 13 was 36.93, intrusion mean=12.25, avoidance mean=10.66, and arousal mean=14.1. Considering the cutoff point of 30 and more for this scale, 138 of children out of 197 which represented $70.1 \%$ were diagnosed as PTSD. To study 
differences in total trauma, and sex of children, a T independent test was performed in which children sex was the dependent variable and total IES variable as independent variable. The result showed that there were no statistically significant differences in total IES scores and sex of children (Table 3).

Table 3: Type of traumatic experiences by parents and children.

\begin{tabular}{|c|c|c|c|c|}
\hline \multirow{2}{*}{ Traumatic Events } & \multicolumn{2}{|c|}{ Parents $(\mathrm{N}=212)$} & \multicolumn{2}{|c|}{ Children $(\mathrm{N}=212)$} \\
\hline & $\mathbf{N}$ & $\%$ & $\mathbf{N}$ & $\%$ \\
\hline $\begin{array}{l}\text { Hearing about killing } \\
\text { of a friend }\end{array}$ & 146 & 68.9 & 128 & 60.4 \\
\hline $\begin{array}{l}\text { Hearing about killing } \\
\text { of a close relative }\end{array}$ & 136 & 64.2 & 127 & 59.9 \\
\hline $\begin{array}{c}\text { Witnessing firing } \\
\text { by tanks and heavy } \\
\text { artillery of neighbor } \\
\text { home }\end{array}$ & 146 & 68.9 & 131 & 61.8 \\
\hline $\begin{array}{l}\text { Witnessing firing } \\
\text { by tanks and heavy } \\
\text { artillery on your home }\end{array}$ & 97 & 45.8 & 97 & 45.8 \\
\hline $\begin{array}{c}\text { Witnessing } \\
\text { bombardment of other } \\
\text { homes by airplanes } \\
\text { and helicopters }\end{array}$ & 197 & 92.9 & 171 & 80.7 \\
\hline $\begin{array}{l}\text { Watching mutilated } \\
\text { bodies and wounded } \\
\text { people on TV }\end{array}$ & 203 & 95.8 & 206 & 97.2 \\
\hline $\begin{array}{l}\text { Witnessing assignation } \\
\text { of people by rockets }\end{array}$ & 188 & 88.7 & 169 & 79.7 \\
\hline $\begin{array}{l}\text { Hearing shelling of the } \\
\text { area by artillery }\end{array}$ & 197 & 92.9 & 200 & 94.3 \\
\hline $\begin{array}{l}\text { Witnessing the signs of } \\
\text { shelling on the ground }\end{array}$ & 194 & 91.5 & 187 & 88.2 \\
\hline $\begin{array}{l}\text { Hearing the sonic } \\
\text { sounds of the } \\
\text { firefighters }\end{array}$ & 200 & 94.3 & 198 & 93.4 \\
\hline
\end{tabular}

In order to test the differences of other socio demographic variables such as number of siblings, place of residence, family monthly income, and age of children (9-11 years, 12-15 years, and 16-18 years), a One Way ANOVA was performed in which each of the socioeconomic variable was the independent variable and total IES as dependent variable. The result showed that there were statistically significant differences in total PTSD and number of siblings and age of children. Post hoc test showed that only children coming from families of 4 and less children had more PTSD than the other two groups (5-7, 8 and more children) $(\mathrm{F}=4.265, \mathrm{p}=0.01)$ and children aged $12-15$ years had more PTSD scores than the other two groups ( $F=3.90, p=.02)$. In order to test the predictive value of specific traumatic events on PTSD symptoms, total IES scores were entered as the dependent variable in linear multiple regressions, with the 10 types of traumatic events as the covariates. No single events were significantly associated with IES scores (Table 4).
Table 4: PTSD, Anxiety, and other mental health problems in children $(\mathrm{N}=197)$.

\begin{tabular}{|c|c|c|c|c|c|}
\hline & $\mathbf{N}$ & Minimum & Maximum & Mean & SD \\
\hline $\begin{array}{c}\text { PTSD } \\
\text { according to } \\
\text { IES }\end{array}$ & 212 & 0 & 65 & 34.66 & 12.2 \\
\hline Intrusion & 209 & 0 & 20 & 11.54 & 4.85 \\
\hline Avoidance & 211 & 0 & 20 & 10.01 & 5.17 \\
\hline Arousal & 209 & 0 & 25 & 13.25 & 6.2 \\
\hline $\begin{array}{c}\text { SDQ Total } \\
\text { Difficulties }\end{array}$ & 212 & 8 & 113 & 18.49 & 8.06 \\
\hline $\begin{array}{l}\text { Hyperactivity } \\
\text { problems }\end{array}$ & 212 & 1 & 106 & 6.58 & 7.04 \\
\hline $\begin{array}{l}\text { Emotional } \\
\text { problems }\end{array}$ & 212 & 0 & 10 & 3.83 & 2.55 \\
\hline $\begin{array}{l}\text { Conduct } \\
\text { problems }\end{array}$ & 212 & 0 & 8 & 3.59 & 1.64 \\
\hline $\begin{array}{l}\text { Peer } \\
\text { relationship }\end{array}$ & 212 & 1 & 8 & 4.82 & 1.56 \\
\hline $\begin{array}{l}\text { Prosocial } \\
\text { behavior }\end{array}$ & 212 & 1 & 10 & 7.69 & 2.09 \\
\hline
\end{tabular}

\section{General mental health problems using SDQ}

Children showed a different symptom, the most common symptom was restless (46.8\%), while the common symptoms were: spiteful to others (4.7\%), and arguing with adults (5.6\%). Using SDQ for parents, 77 children (42.7\%) were rated as having psychological morbidity by parents using (17-40) cut off points. Regarding hyperactivity, 43 children $(22.8 \%)$ were considered hyperactive by their parents, 71 children $(36.8 \%)$ had conduct problems, 46 children (24.4\%) had emotional problems, 114 children $(60.1 \%)$ had peer problems, and 39 children (20.2) had prosocial problems. A T independent test was performed to reveal differences in total SDQ and children sex the result showed that there were no statistically significant differences in total SDQ scores and sex of children (Table 5).

Table 5: Means and SD of trauma, PTSD, and anxiety in parents $(\mathrm{N}=212)$.

\begin{tabular}{|c|c|c|c|c|c|}
\hline \multicolumn{1}{|c}{ N } & \multicolumn{1}{c}{ Minimum } & \multicolumn{1}{c|}{ Maximum } & Mean & SD \\
\hline $\begin{array}{c}\text { Total } \\
\text { traumatic } \\
\text { events }\end{array}$ & 211 & 0 & 23 & 8.14 & 2.34 \\
\hline $\begin{array}{c}\text { Total score } \\
\text { of PTSD } \\
\text { scale }\end{array}$ & 212 & 25 & 77 & 49.37 & 11.95 \\
\hline Intrusion & 212 & 6 & 25 & 16.76 & 4.28 \\
\hline Avoidance & 211 & 8 & 33 & 18.36 & 5.08 \\
\hline Arousal & 210 & 5 & 25 & 14.22 & 5.07 \\
\hline $\begin{array}{c}\text { Total } \\
\text { Manifest } \\
\text { Anxiety } \\
\text { Scale }\end{array}$ & 212 & 6 & 60 & 27.93 & 8.21 \\
\hline
\end{tabular}

One Way ANOVA was performed in which each of the socioeconomic variable was the independent variable and total SDQ scores were entered as dependent variable. No significant 
differences in total SDQ scores in children and number of sibling, place of residence, age of children, and family monthly income. The association between exposure to traumatic events and PTSD symptoms, and general mental health problems rated by parents was investigated. IES scores were significantly associated with the total number of experienced traumatic events (Spearman rank correlation coefficient: $\mathrm{r}=0.22, \mathrm{p}=0.001)$. The same was applied to each IES subscale: intrusion $(\mathrm{r}=.48, \mathrm{p}=0.001)$, and arousal $(r=0.30, p=0.001)$, and no correlation with avoidance subscale. Arousal subscale in children $(r=0.25, p=0.001)$ was significantly associated with total SDQ of parents (Table 6).

Table 6: Anxiety disorder in parents.

\begin{tabular}{|c|c|c|}
\hline \multicolumn{3}{|l|}{$\begin{array}{c}\text { Anxiety Disorder in } \\
\text { Parents }\end{array}$} \\
\hline No anxiety & 88 & 41.5 \\
\hline Mild anxiety & 59 & 27.8 \\
\hline Moderate & 58 & 27.4 \\
\hline Severe anxiety & 7 & 3.3 \\
\hline PTSD of parents & $\mathrm{N}$ & $\%$ \\
\hline PTSD & 104 & 49.1 \\
\hline No PTSD & 108 & 50.9 \\
\hline \multicolumn{3}{|l|}{ PTSD of children } \\
\hline PTSD & 138 & 65.1 \\
\hline No PTSD & 74 & 34.9 \\
\hline \multicolumn{3}{|l|}{ Anxiety } \\
\hline Anxiety & 67 & 31.6 \\
\hline No anxiety & 145 & 68.4 \\
\hline
\end{tabular}

\section{Anxiety symptoms and level in children}

This study showed that the most common anxiety symptoms in children were feeling tired (75\%), feeling alone $(72.5 \%)$, stomachache $(63 \%)$, feelings that others are against them $(62.5 \%)$. In order to find the differences between children anxiety symptoms, a non parametric Mann-Whitney Test was done. The results showed that girls were more anxious to what she may face in future $(\mathrm{z}=-2.42, \mathrm{p}=0.01)$, irritability $(\mathrm{z}=-2.15$, $\mathrm{p}=0.03)$, anxious about what others will say $(\mathrm{z}=-1.95, \mathrm{p}=0.05)$, feelings that many people are against her $(\mathrm{z}=-1.9, \mathrm{p}=0.05)$. According to Revised Children's Manifest Anxiety Scale, mean anxiety was $15.83(\mathrm{SD}=5.2)$. Considering cutoff point of 19 and more as anxiety, 67 children representing (31.6\%) had scored above the cutoff point as anxiety disorder. To study differences in total anxiety scores, and sex of children, a T independent test was performed in which children sex was the dependent variable and total anxiety scores variable as independent variable. The result showed that there were no statistically significant differences in total anxiety scores and sex of children.

In order to test the predictive value of specific PTSD symptoms on anxiety disorder, total anxiety scores were entered as the dependent variable in linear multiple regressions, with the 13 symptoms of PTSD as the covariates. The results showed that the following PTSD symptoms predicted anxiety in children: think about it even when you don't mean to $(B=0.50, p=0.02)$, startle more easily or feel more nervous than did before the event $(\mathrm{B}=0.64, \mathrm{p}=0.002)$, insomnia $(\mathrm{B}=0.44, \mathrm{p}=0.03)$, and difficulties paying attention or concentrating $(B=2.02, p=0.02)$. While stay away from reminders of trauma (e.g. places or situations) was negatively predicted the anxiety $(B=-0.47, p=0.02$ ), (Table 7).

Table 7: Sixty nine of boys who represented $69 \%$ of boys and 69 girls who represented $71.1 \%$ of girls scored as PTSD.

\begin{tabular}{|c|c|c|}
\hline PTSD of Children & & \\
\hline PTSD & 138 & 65.1 \\
\hline No PTSD & 74 & 34.9 \\
\hline
\end{tabular}

The association between anxiety scores and trauma, PTSD, and general mental health of children, and emotional problems was investigated. Anxiety scores were significantly associated with the total number of experienced traumatic events (Spearman rank correlation coefficient: $r=0.22, p=0.003$ ). The same applied to intrusion ( $\mathrm{r}=.31, \mathrm{p}=0.001)$, arousal $(\mathrm{r}=0.44, \mathrm{p}=0.001)$, and emotional problems $(\mathrm{r}=.19, \mathrm{p}=0.01)$. No correlations were found between total score of IES and total anxiety scores in children. One Way ANOVA was performed in which each of the socioeconomic variable was the independent variable and total anxiety scores were entered as dependent variable. No significant differences in total anxiety scores and number of sibling, place of residence, age of children, and family monthly income.

\section{Parental traumatic events}

Palestinians experienced a variety of traumatic experiences; the most common traumatic events reported by the parents were watching mutilated bodies and wounded people on TV (98.5\%), witnessing the signs of shelling on the ground $95 \%$, hearing the sonic sounds of the jetfighters (94\%), and witnessing bombardment of other homes by airplanes and helicopters (93\%). Parents mean traumatic events were 8.5 (SD=1.68). In order to study differences in total traumatic events, and sex of parents, a T independent test was performed. The result showed that there were no statistically significant differences in total traumatic events and sex of parents. The association between 
exposure to traumatic events and PTSD symptoms, and anxiety disorder in parents was investigated. PTSDC scores were not associated with the total number of experienced traumatic events (Pearson rank correlation coefficient). Total traumatic events was significantly associated with intrusion $(r=.30$, $\mathrm{p}=0.001$ ).

\section{Post traumatic stress symptoms in parents}

Parents reported a different reactions to traumatic events, the most common reactions were: flashbacks $(68.5 \%)$, psychologic reactivity (59\%), intrusive memories (59\%), and amnesia (51\%). Parents mean PTSDC items was $51.6(\mathrm{SD}=11.8)$, intrusion mean=17.5 (SD=4.05), avoidance mean=19.65 $(\mathrm{SD}=5.3)$, and arousal mean=14.9 $(\mathrm{SD}=4.84)$. Considering the cutoff point of 50 and more for this scale, 120 parents who represented $60 \%$ scored as PTSD. In order to study differences in total traumatic events, and sex of parents, a T independent test was performed. The result showed that there were statistically significant differences in total PTSD scores and sex of parents toward mothers $(\mathrm{t}=-2.00, \mathrm{p}=0.04)$.

The association between PTSD symptoms, intrusion, avoidance, hyper arousal, and anxiety scores in parents was investigated. PTSDC scores were significantly associated with intrusion $(\mathrm{r}=0.64, \mathrm{p}=0.001)$, avoidance $(\mathrm{r}=0.82, \mathrm{p}=0.001)$ and arousal subscale $(\mathrm{r}=0.83, \mathrm{p}=0.001)$. PTSD score was significantly associated with anxiety $(\mathrm{r}=0.47, \mathrm{p}=0.001)$. The result showed that intrusion was associated with anxiety $(\mathrm{r}=0.41, \mathrm{p}=0.001)$, avoidance $(\mathrm{r}=0.29, \mathrm{p}=0.001)$, and hyper arousal $(0.51, \mathrm{p}=0.01)$ In order to test the predictive value of specific traumatic events on PTSD symptoms, total PTSDC scores were entered as the dependent variable in linear multiple regressions, with the 10 types of traumatic events as the covariates. The event that was significantly associated with PTSDC scores was witnessing shelling and destroying of own house $(B=4.92, S E=1.90$, Beta $=0.20, t=2.58, p=0.01$ ) and witnessing bombardment of other homes by airplanes and helicopters $(B=10.02, S E=3.83$, Beta $=0.21, \mathrm{t}=2.61, \mathrm{p}=0.01$ ).

\section{Anxiety disorder in parents}

This study showed that the most common anxiety symptoms in parents were: insomnia (95\%), like to be happy like others (93\%), anxious of unknown (84.5\%), and inability to go to sleep and awake many times at night (82.5). Parents mean Taylor anxiety scale was 28.05 (SD=7.08). Following the cutoff point of 33 and more as severe to very severe anxiety, $26.5 \%$ of parents scored as severe to very severe anxiety. In order to find the differences between parents in anxiety symptoms, a non parametric Mann-Whitney Test was done. The results showed that mothers had disturbed sleep more than father $(\mathrm{z}=-2.04, \mathrm{p}=0.04)$, nightmares was more in mothers $(\mathrm{z}=-1.91$, $\mathrm{p}=0.05)$, tremors of hands $(-2.12, \mathrm{p}=0.001)$, flushing of face $(-2.57, \mathrm{p}=0.01)$, nausea $(\mathrm{z}=-2.1, \mathrm{p}=0.04)$, weeping easily $(-6.43$, $\mathrm{p}=0.000)$, concentration in something $(-2.7, \mathrm{p}=-0.007)$, and easily embarrassed $(\mathrm{z}=-2.9, \mathrm{p}=0.003)$. In order to study differences in total anxiety scores, and sex of parents, a $\mathrm{T}$ independent test was performed. The result showed that there were statistically significant differences in total anxiety scores and sex of parents toward mothers $(\mathrm{t}=-2.53, \mathrm{p}=0.01)$.

To test the differences in total anxiety scores of parents and other socioeconomic variables, One Way ANOVA was performed in which each of the socioeconomic variable was the independent variable and total anxiety scores were entered as dependent variable. No statistically significant differences in total anxiety scores in parents and number of sibling, place of residence, and family monthly income. The association between anxiety and intrusion, avoidance, and hyper arousal in parents was investigated. Anxiety score was significantly associated with intrusion ( $\mathrm{r}=0.41, \mathrm{p}=0.001)$, avoidance $(\mathrm{r}=0.29, \mathrm{p}=0.001)$, and hyper arousal $(0.51, \mathrm{p}=0.01)$.

In order to test the correlation between scores of children trauma, PTSD, and anxiety and parents similar items Spearman correlation test was performed. The result showed that total IES score of children was significantly associated with total traumatic events of parents $(r=.15, p=0.03)$, total Taylor anxiety scale of parents $(r=.18, p=0.01)$, total score of PTSD of parents $(r=.22$, $\mathrm{p}=0.002)$, intrusion scale of parents $(\mathrm{r}=.26, \mathrm{p}=0.001)$, avoidance $(\mathrm{r}=.16, \mathrm{p}=0.03)$, and arousal subscale $(\mathrm{r}=.21, \mathrm{p}=0.003)$. Also total score of anxiety of children was significantly correlated with parents total anxiety score $(r=0.39, \mathrm{p}=0.001)$.

\section{Discussion}

This study was conducted to determine the effect of shelling and other traumatic events on parents and children in the Gaza Strip. In this study of families exposed to continuous traumatic events especially shelling of their area days and nights and witnessing traces and remnants of the of such shelling put those families in risk of developing post traumatic stress reactions and anxiety disorder. It was obvious that both parents and children reported similar number of traumatic events besides the shelling; the most common traumatic event was watching mutilated bodies on TV. This is consistent with previous studies in the same population $[4,7,8]$. This result showed the major effect of media on families and their children as Palestinian families are spending much time in watching TV following the news and because no other alternative leisure activities for children and parents. This augmented the cumulative effect of trauma on children and families and postponed recovery from traumatic experiences. Added to these traumatic experiences is the sonic sounds of the jetfighters and effect of children and families mental wellbeing. For parents, witnessing shelling and destroying of own house and witnessing bombardment of other homes by airplanes and helicopters is the strong predictors to PTSD in adults. However, for children we did not find specific traumatic events predicting the PTSD in children. This is similar to our previous study of Palestinians during Al Aqsa Intifada [4]. Comparing our results which showed that both parents and children reported more than 8 traumatic events is consistent 
with similar studies of area exposed to war and armed conflict [11]. Our findings that $61 \%$ of parents were rated as PTSD and no gender differences was consistent with previous study of Kosovon Albania refugee in UK in which $65 \%$ were diagnosed as PTSD and no gender differences in PTSD [21]. This is consistent with study of [10] of Khmer refugee in which the rate of PTSD was (62\%) (Table 8$)$.

Table 8:

\begin{tabular}{|c|c|c|c|}
\hline Abnormal & Borderline & Normal & \\
\hline 60.4 & 20.8 & 18.9 & $\begin{array}{c}\text { SDQ Total } \\
\text { Difficulties }\end{array}$ \\
\hline 47.2 & 22.2 & 30.7 & Conduct problems \\
\hline 40.6 & 13.7 & 45.8 & Emotional problems \\
\hline 40.6 & 13.7 & 45.8 & $\begin{array}{c}\text { Hyperactivity } \\
\text { problems }\end{array}$ \\
\hline 79.2 & 13.2 & 7.5 & Peer relationship \\
\hline 8 & 5.7 & 86.3 & Prosocial behavior \\
\hline
\end{tabular}

Our rate of PTSD was inconsistent with [22] study of civilian population from southern Lebanon found that almost all participants, 97.7\%, had experienced, witnessed, or heard of a war-related traumatic event. Current PTSD prevalence was $29.3 \%$. PTSD symptoms correlated highly with GHQ-28 symptoms. Our findings that mean of anxiety in parents (28.05) is very similar to study of [16] of demolished family houses in Gaza Strip during the previous Intifada (mean anxiety=28.5). Our findings of significant association between anxiety disorder of children and parents was consistent with previous study of children and mother in which girls anxiety was related to mothers anxiety and depression [4].

In this study $70.1 \%$ of children were diagnosed as PTSD which is higher than rate of PTSD in previous studies [5-7]. This high rate of PTSD in this sample could be due to the fact that children and families are exposed to extremely threatening traumatic events involved daily shelling of the area by tanks and heavy arterially. The proximity of such families to the border and previous exposure to incursion is superadded stress and trauma on those families. This finding is inconsistent of study of [23] of school age children with rate of $34.1 \%$ of PTSD in children living in West Bank. [6] In study of PTSD in Palestinian children exposed to military violence showed that (54\%) of the children were suffering from a severe level of PTSD symptoms, and a third from a moderate level. Our results are higher than other studies of levels of PTSD among Cambodian [24], and BosniaHerzegovina [25] refugee children fleeing atrocities in their respective home countries. But, our findings are lower than that reported among Iraqi children after the first gulf war (84\%) [26].

Our findings that there was no gender difference in PTSD are consistent with previous studies $[4,7,8]$. This result was inconsistent with other studies, with more girls than boys qualifying for the diagnosis of PTSD, while boys show higher rates of behavior symptoms [27]. Also our result is inconsistent with [22] who found that Palestinian boys in West Bank were diagnosed as PTSD than girls. Findings of correlation between trauma and PTSD of children are consistent with previous research. The greater the number and severity of prior traumatic events experienced, the more severe prior PTSD symptoms are likely to have been [20]. Furthermore, additional traumatic events have the potential to reignite prior PTSD symptomatology in trauma-exposed individuals [28].

The study found a positive correlation between child and parent PTSD symptoms may suggest interactive effects between child and parent psychopathology. Parent under shelling and exposed to other traumatic may find it difficult to help children cope with avoidance if they are similarly affected. The study result was consistent with Chrestman [29] and Danieli [30] who asserted that the distinction between primary and secondary traumatisation is academic. This was consistent with study of children admitted to pediatric intensive care unit [31] which found a positive correlation between PTSD symptoms in parents and PTSD symptoms in the child.

Our findings that $42.7 \%$ of children were rated as having mental health problems according to parents are greater than was found previously in other studies where there is no conflict. [32] Found prevalence of mental health problems in $12.4 \%$ of French 8-11 year-olds. In a previous epidemiological study in the Gaza strip, the authors used the SDQ in a sample of 3-16 year-old-children and found lower prevalence rates, in early and middle childhood, the established rates of psychiatric cases (10.9\% at age $3,11.1 \%$ at age 6 , and $16.3 \%$ at age 11 ) [20]. Also, Thompson et al. [33] estimated prevalence rates of $13.2 \%$ for mental health problems. Differences among the studies may reflect differences in the optimal cut-off points and differences in method of investigation. Consistence with our previous study of Palestinian children in West Bank and Gaza Strip [8].

\section{Conclusion}

The present study highlights the need for establishment of crisis intervention center in north of Gaza to help such families of overcoming their anxiety and PTSD with their children. Also, there is a great need of parental education about meaning of trauma, preparedness of children in face of traumatic events such as shelling through public meetings with mothers and fathers. Involvement of local and international NGOs in the area to establish psychosocial programmes for such family is urgently needed. Intervention programmes for children and families must consider the large number of children and parents with mental health problems and using group techniques will be more efficient for such targeted population (Table 9).

Table 9: Revised children's manifest anxiety.

\begin{tabular}{|c|c|c|}
\hline Anxiety & & \\
\hline Anxiety & 67 & 31.6 \\
\hline No anxiety & 145 & 68.4 \\
\hline
\end{tabular}

\section{Acknowledgment}

Our thanks to the team collected the data under shelling and difficulties. Also many thanks to families and children who 
participate in this study and their openness of discussion their fears and trauma.

\section{Referances}

1. (2006) United Nations. Situation in the Gaza Strip. August, Report, USA.

2. (1994) American Psychiatric Association. Diagnostic and statistical manual of mental disorders $\left(4^{\text {th }} e d n\right)$, American Psychiatric Association, USA.

3. De Jong J, Komproe I, Van Ommeren M, El Masri M, Araya M, et al (2001) Lifetime events and posttraumatic stress disorder in 4 postconflict settings. JAMA 286(5): 555-562.

4. Thabet AA, Abed Y, Vostanis P (2001) The effect of trauma on Palestinian children and mothers mental health in the Gaza Strip. East Mediterr Health J 7(3): 314-321.

5. Thabet AA, Abed Y, Vostanis P (2002) Emotional problems in Palestinian children living in a war zone: a cross-sectional study. Lancet 359(9302): 1801-1804.

6. Qouta S, Punamaki RL, El Sarraj E (2003) Prevalence and determinants of PTSD among Palestinian children exposed to military violence. Eur Child Adolesc Psychiatry 12(6): 265-272.

7. Thabet AA, Abed Y, Vostanis P (2004) Comorbidity of post-traumatic stress disorder and depression among refugee children during war conflict. J Child Psychol Psychiatry 45(3): 533-542.

8. Thabet AA, Abdulla T, El Helou M, Vostanis P (2006) Effect of trauma on children mental health in the Gaza Strip and West. In: Greenbaum CW, Veerman P, Bacon-Shnoor N (Eds.), Protection of children during armed political conflict a multidisciplinary perspective.

9. Pham PN, Weinstein H, Longman T (2004) Trauma and PTSD ymptoms in Rwanda. Implications for attitudes toward justice and reconciliation. JAMA 292(5): 602-612.

10. Marshall GN, Schell TL, Elliott MN, Berthold M, Chun C (2005) Mental Health of Cambodian Refugees 2 Decades After Resettlement in the United States. JAMA 294(5): 571-579.

11. Basoglu M, Livanou M, Crnobaric C, Franciskovic T, Suljic E, et al. (2005) Psychiatric and cognitive effects of war in Former Yugoslavia association of lack of redress for trauma and posttraumatic stress reactions. JAMA 294(5): 580-590.

12. Taylor JA (1953) A personality scale of manifest anxiety. J Abnorm Psychol 48(2): 285-290.

13. Reynolds CR, Richmond BO (1978) What I Think and Feel: A revised measure of children's manifest anxiety. J Abnorm Child Psychol 6(2): 271-280.

14. Reynolds CR, Richmond BO (1978) What I Think and Feel: A measure of children's manifest anxiety. J Abnorm Child Psychol 6(2): 271-280.

15. Souife A (1976) Social psychology. El Anglo, Egypt.

16. Qouta S, Punamak RL, El Sarraj E (1988) House demolition and mental health: Victims and witnesses. Journal of Social Distress and the Homeless 7(4): 279-288
17. Smith P, Perrin S, Dyregrov A, Yule W (2003) Principal components analysis of the Impact of Event Scale with children in war. Personality and Individual Differences 34: 315-322.

18. Horowitz M, Wilner N, Alvapez W (1979) Impact of Event Scale: a measure of subjective stress. Psychosom Med 41(3): 209-218.

19. Perrin S, Meiser-Stedman R, Smith P (2005) The Children's revised impact of event scale (CRIES): Validity as a screening instrument for PTSD. Behavioural and Cognitive Psychotherapy 33(4): 487-498.

20. Thabet AA, Stretch D, Vostanis P (2000) Child mental health problems in Arab children: application of the Strengths and Difficulties Questionnaire. Int J Soc Psychiatry 46(4): 266-280.

21. Turner S, Bowie C, Dunn G, Shapo L, Yule W (2003) Mental health of kosovan albanian refugee in the UK. Br J Psychiatry 182: 444-448.

22. Farhood L, Dimassi Lehtinent T (2006) Exposure to war-related traumatic events, Prevalence of PTSD, and general psychiatric morbidity in a civilian population from southern Lebanon. J Transcult Nurs 17(4): 333-340.

23. Khamis V (2005) Post-traumatic stress disorder among school age Palestinian children. Child Abuse \& Negle 29(1): 81-95.

24. Kinzie JD, Sack WH, Angel RH, Manson S, Rath B (1996) The psychiatric effect of massive trauma on Cambodian children: I. The children. J Am Acad Child Psychiatry 25(3): 370-376.

25. Smith P, Perrin S, Yule W, Hacam B, Stuvland R (2002) War exposure among children from Bosnia-Hercegovina: psychological adjustment in a community sample. Journal of Trauma Stress 15(12):147-156.

26. Dyregrov A, Gjestad R, Raundalen M (2002) Children exposed to warfare: a longitudinal study. J Trauma Stress 15(1): 59-68.

27. Yule W, Perrin S, Smith P (1999) Post-traumatic stress reactions in children and adolescents. In: Yule W (Ed.) Post-traumatic stress disorders: Concepts and therapy. Chichester John Wiley \& Sons, England.

28. Zea MC, Diehl VA, Porterfield KS (1996) Central American youth exposed to war violence. In: JG, Garcia MC, Zea (Eds.), Psychological interventions and research with Latino populations. Allyn \& Bacon Boston, USA, pp. 39-55.

29. Chrestman KR (1994) Secondary traumatization in therapists working with survivors of trauma. Unpublished doctoral dissertation, Nova University, Fort Lauderdale, Florida, USA.

30. Danieli $Y$ (1998) International handbook of multigenerational legacies of trauma, New York, USA, pp. 24-26.

31. Rees G, Gledhill J, Garralda ME, Nadel S (2004) Psychiatric outcome following paediatric intensive care unit (PICU) admission: a cohort study. Intensive Care Med 30(8): 1607-1614.

32. Fombonne E (1994) The Charters study. Prevalence of psychiatric disorders among French school-aged children. British Journal of Psychiatry 164: 69-79.

33. Thompson M, Stevenson J, Sonuga-Barke E, Nott P, Bhatti Z, et al (1996) Mental health of pre-school children and their mothers in a mixed urban/rural population. I. Prevalence and ecological factors. $\mathrm{Br}$ J Psychiatry 168(1): 16-20. 
(C) This work is licensed under Creative BY Commons Attribution 4.0 License

\section{Your next submission with Juniper Publishers} will reach you the below assets

- Quality Editorial service

- Swift Peer Review

- Reprints availability

- E-prints Service

- Manuscript Podcast for convenient understanding

- Global attainment for your research

- Manuscript accessibility in different formats

( Pdf, E-pub, Full Text, Audio)

- Unceasing customer service

Track the below URL for one-step submission https://juniperpublishers.com/online-submission.php 